\title{
NATURALEZA PROCESAL DEL PROCESO CONSTITUCIONAL DE CUMPLIMIENTO
}

Fabiola García Merino*

Recibido: 12.09.2014

Aprobado: 20.10.2014

\section{RESUMEN}

La naturaleza procesal del proceso constitucional de cumplimiento se respalda en el writ of mandamus que es el primer antecedente de lo que en el derecho constitucional peruano ha establecido como el mandato, definido como manifiesto de una obligación que debe cumplir el Estado frente a un ciudadano. En el caso del ordenamiento público peruano, se ha configurado como un proceso constitucional que defiende frente a la inactividad de la Administración Pública de cumplir con un mandato legal o un acto administrativo.

\section{PALABRAS CLAVE}

Writ of mandamus - Mandato - Proceso constitucional de Cumplimiento - Inactividad de la Administración Pública Mandato legal - Acto administrativo.

\section{ABSTRACT}

The constitutional process of compliance is supported in the writ of mandamus which is the preceding of what the Peruvian constitutional law established as an obligation to be fulfilled by the state. In the case of the peruvian public order, it is configured as a constitutional process that advocates against the inactivity of public administration to comply with a legal or administrative writ.

\section{KEY WORDS}

Writ of mandamus - Writ - Constitutional process of compliance - Inactivity of public administration - Legal or administrative writ.

\section{AnteCedentes $y$ obJeto de PROTECCIÓN}

El inciso 6 del artículo $200^{\circ}$ de la Constitución Política del Estado de 1993 incorporó la figura del proceso de cumplimiento, señalando que procede contra cualquier autoridad o funcionario renuente a acatar una norma legal o un acto administrativo.
La acción de cumplimiento se asemeja al "writ of mandamus" norteamericano. En efecto, como señala Fix Zamudio, aquel "implica la solicitud ante un tribunal para que expida un mandamiento que ordene a una autoridad que cumpla con las atribuciones que le confieren las disposiciones legales". Este writ ha tenido una influencia apreciable en algunos países latinoamericanos, como por ejemplo, en la Constitución de Colombia de 1991 y en los ordenamientos procesales de ciertas provincias argentinas.

Es un proceso constitucional que tiene su origen en el derecho inglés, cuyos orígenes se remontan al siglo XVI, data en la

\footnotetext{
* Abogada CUM LAUDE por la UNIFE. (Lima, 2003). Doctorado en Derecho Político. UNED. (Madrid 2007). Catedrática de los cursos de Derecho Internacional Privado y Derecho Internacional Público en la Facultad de Derecho de la Universidad Femenina del Sagrado Corazón (Lima, 2012).
} 
que aproximadamente se forja el Writ of Mandamus. De allí se expande a los Estados Unidos y paulatinamente se irradia en líneas generales a ciertos países, como es el caso de Colombia, algunas constituciones provinciales de Argentina, y el Perú.

\section{WRIT OF MANDAMUS}

Los actuales writ, denominación que aún mantienen los mecanismos o procesos que se han establecido en el derecho inglés, tienen sus antecedentes en los denominados King's Writs, que hacia el siglo XII el Rey inglés institucionaliza en el manejo de la cosa pública. Inicialmente fueron órdenes que empleaba el Rey para desplegar sus tropas, cobrar impuestos, nombrar funcionarios y realizar diversos actos públicos. Después, y como consecuencia de su frecuente uso en el ámbito del acceso a los tribunales de la Corona, toman la forma de decretos, mandamientos, proveídos u órdenes dictados por el Rey con el objeto de que los jueces y tribunales de la Corona tomaran conocimiento de los procesos promovidos por los súbditos ingleses. Con el paso del tiempo, se convirtieron en proveídos dictados por los jueces, dirigidos al demandado en un proceso "para comparecer en juicio a contestar la demanda, rendir pruebas y formular alegaciones" .

En la actualidad, los Writs del derecho procesal inglés son la denominación que reciben los mecanismos procesales que allí se prevén en materia penal, civil, etc., y así ha sido recepcionado también en el Derecho Norteamericano. En este último país, como recuerda Fix Zamudio, desde 1938 el nomen de writs ha variado por el de Prerrogative orders, que comprende, además de los procedimientos de prohibition y certiorari, al Mandamus.

El Writ of Mandamus, cuya aparición como tal se remonta al siglo XIV, constituye un proceso judicial cuyo objeto es obtener un mandato del Juez por virtud del cual se ordena que las autoridades cumplan con sus obligaciones. Según su definición clásica, "es el mandamiento que dicta un tribunal competente en nombre del Estado o soberano, dirigido a otro tribunal inferior o a cualquier autoridad administrativa, ordenando la ejecución de un deber impuesto por la ley" .

En su versión norteamericana, cabe interponer el Writ o la prerrogative orders of mandamus por obligaciones no discrecionales de las autoridades, no encontrándose entre las personas contra las que se puede promover el Presidente de la República; por lo general, tampoco los Secretarios de Estado, el Congreso de la Unión, las legislaturas estaduales y los gobernadores de Estados; en tanto que el Poder Judicial no es competente para ordenar ejecuten sus deberes o ejerzan sus facultades, pues se entiende que el ejercicio de tales atribuciones constituyen cuestiones políticas no justiciables. En todos los demás casos, a través del Writ of Mandamus se exige el cumplimiento de las obligaciones que imponen las leyes a los funcionarios.

\section{Naturaleza procesal del Proceso de Cumplimiento}

Uno de los rasgos comunes del derecho constitucional lati- noamericano de los últimos 20 años, consiste en haber introducido una diversidad de mecanismos procesales de defensa de la Constitución y, al mismo tiempo, haberlos abordado de espaldas a la teoría general del proceso, esto es, con relación al estudio "en conjunto y con un criterio común (de los) principios generales" aplicables a todas las ramas del Derecho Procesal, independientemente de las particularidades que cada una de ellas posea.

Es un proceso, pues se trata de un mecanismo instrumental compuesto por un conjunto de actos jurídico procesales concatenados entre sí de modo ordenado, a través del cual una o varias pretensiones litigiosas, invocadas por los justiciables, son resueltas por los órganos de la jurisdicción, aplicando el derecho objetivo, con el objeto de restablecer la paz social y la justicia.

Este proceso constitucional procede contra toda autoridad o funcionario que se muestre renuente a acatar lo dispuesto en una norma legal o en un acto administrativo, esto es, constituye un mecanismo de control de la inactividad de la Administración; conlleva que, por la función que cumple, se le considere como un proceso en cuyo seno pueden resolverse dos clases de pretensiones:

En ese sentido, siguiendo a Allan Brewer Carías, bien puede decirse que el proceso de Cumplimiento "contra la carencia de la Administración no persigue que sólo se declare la ilegalidad de la omisión...de la Administración..., sino lo que se persigue, es que formalmente se ordene 
a la Administración adoptar determinados actos, o si ello no es suficiente para amparar el derecho, que el Juez restablezca por sí mismo la situación jurídica violada ".

Un sector importante de la doctrina latinoamericana ha expresado una respuesta afirmativa al señalar que el proceso de cumplimiento es un proceso constitucional.

$Y$ es que lo que caracteriza a un proceso como constitucional es la presencia conjunta de los siguientes elementos: a) Su configuración o creación a nivel constitucional, y no simplemente mediante una ley; b) Existencia autónoma, esto es, con entidad propia, y no sólo como un elemento accesorio que forme parte de un proceso distinto, como puede ser el caso de los "incidentes constitucionales"; y, c) Su objeto, esto es, un proceso destinado a resolver controversias en materia constitucional, y no de otra clase, mediante una ley.

En ese sentido, aun cuando de los tres elementos, el proceso de cumplimiento cumpla con los dos primeros, la carencia del tercero parece ser de tal envergadura que basta, por sí sola, para enrarecer su condición de proceso constitucional. $Y$ es que si la controversia en este proceso se deriva esencialmente de la inactividad, omisión o renuencia a no cumplir con los mandatos establecidos en una ley o en un acto administrativo, entonces puede decirse, sin temor a equivocarse, que se trata de un proceso destinado a controlar la ilegalidad por omisión de la Administración Pública. No hay, pues, controversia que gire sobre "materia constitucional", ya que su objeto no se plantea como consecuencia de la aplicación o vigencia de una norma constitucional, sino de la ley o el acto administrativo.

Sin embargo, César Landa ha advertido que su objeto sería velar "por la vigencia de dos derechos constitucionales positivos: uno, la constitucionalidad de los actos legislativos $y$, el otro, la legalidad de los actos administrativos". En tal sentido, ha afirmado que, "no basta que una norma legislativa o administrativa sea aprobada mediante los requisitos formalmente y que sea conforme a las disposiciones sustantivas establecidos en la Constitución y en la ley, sino que la eficacia del cumplimiento de las mismas se convierte en un derecho constitucional de los ciudadanos."

\section{INACTIVIDAD ADMINISTRATIVA $Y$ PROCESO DE CUMPLIMIENTO}

El artículo $87^{\circ}$ de la Constitución colombiana establece que "Toda persona podrá acudir ante la autoridad judicial para hacer efectivo el cumplimiento de la ley o un acto administrativo..." En tanto que el inciso 6) del artículo 200 de la Constitución peruana, señala que "procede la acción de cumplimiento, contra autoridad o funcionario, por la renuencia a cumplir con lo dispuesto en la ley o acto administrativo".

En ambos casos, la controversia se origina tras la existencia de una omisión, mora, letargo, inercia o, simplemente, inactividad de un órgano público para cumplir con un mandato establecido en la ley o un acto administrativo. Sin embargo, no cualquier inactividad administrativa se persigue condenar como ilegítima en el seno del proceso de cumplimiento.

Lo referido anteriormente se sustenta en lo que el Tribunal Constitucional, en su sentencia STC N00168-2005-AC, estableció en los fundamentos jurídicos 14 y $15:$

"Para que el cumplimiento de la norma legal, la ejecución del acto administrativo y la orden de emisión de una resolución sean exigibles a través del proceso de cumplimiento, además de la renuencia del funcionario o autoridad pública, el mandato contenido en aquellos deberá contar con los siguientes requisitos mínimos comunes:

a) Ser un mandato vigente.

b) Ser un mandato cierto y claro, es decir, debe inferirse indubitablemente de la norma legal o del acto administrativo.

c) No estar sujeto a controversia compleja ni a interpretaciones dispares.

d) Ser de ineludible y obligatorio cumplimiento.

e) Ser incondicional.

Excepcionalmente, podrá tratarse de un mandato condicional, siempre y cuando su satisfacción no sea compleja y no requiera de actuación probatoria. Adicionalmente, para el caso del cumplimiento de los actos administrativos, además de los requisitos mínimos comunes mencionados, en tales actos se deberá:

f) Reconocer un derecho incuestionable del reclamante.

g) Permitir individualizar al beneficiario." 
4.1. La Inactividad Administrativa: inactividad formal e inactividad material de la administración

Con el propósito de esclarecer el tipo de inactividad administrativa susceptible de control mediante el proceso de cumplimiento, tal vez sea útil, siguiendo a la doctrina administrativa, señalar que tales comportamientos omisivos pueden clasificarse, según se haya o no hecho ejercicio del derecho de petición o se derive de la participación del particular en un procedimiento administrativo, en inactividad formal y material.

Se entiende que existe inactividad formal de la Administración cuando al cabo de un procedimiento administrativo, o como consecuencia del ejercicio del derecho de petición por el administrado, los funcionarios, autoridades u órganos de la Administración no contestan o resuelven lo que se peticiona, no obstante existir un deber de hacerlo. En cambio se presentará una inactividad material de la administración, cuando fuera de un procedimiento administrativo, sus órganos o funcionarios dejan de cumplir un mandato que impone un tipo de actuación.

En nuestro ordenamiento jurídico, como ha indicado Jorge Danós, para que el administrado no se perjudique con la inactividad formal de la Administración, se ha previsto la técnica del silencio administrativo negativo. El silencio no constituye propiamente un acto de la Administración por virtud del cual se genera una denegatoria ficta de la petición o del medio impugnatorio propuesto, sino simplemente una técnica destinada a garantizar que el administrado, ante la ausencia de pronunciamiento administrativo, pueda acceder a la siguiente instancia prevista en esa sede, o en su caso, ante el órgano jurisdiccional.

Porque no supone acto presunto alguno, y sí más bien un mecanismo que impide que el administrado pueda quedar inerme por la ausencia de pronunciamiento, el silencio negativo debe entenderse como una "garantía procesal de los particulares (que) tiene por objetivo evitar que la Administración eluda el control jurisdiccional mediante el simple expediente de permanecer inactiva sin resolver el procedimiento iniciado por el particular" .

Ausente un pronunciamiento formal de los órganos de la Administración, no es el proceso de Cumplimiento el mecanismo a través del cual el administrado podrá exigir que los órganos de la Administración resuelvan lo peticionado, pues de acuerdo a la Ley de Normas Generales de Procedimientos Administrativos, vencido el plazo para que éstos se pronuncien, el administrado podrá optar o bien por esperar el pronunciamiento expreso de la Administración, o bien por acudir a la instancia administrativa o judicial que corresponda, con el objeto de dilucidar allí su reclamación.

Desde esa perspectiva, puede decirse que el proceso de cumplimiento no procede contra la inactividad formal de la Administración, pues ello no sólo importaría restarle operatividad al silencio administrativo negativo, sino desnaturalizar el objeto del proceso al exigirse tácitamente el tránsito por una vía judicial que se presenta como irrazonable, pues, en un primer momento, y ante la inexistencia de respuesta alguna a su petición o impugnación, el particular tendría que exigir, a través de este proceso, que se ordene emitir un pronunciamiento; y, en un segundo momento, luego de haberlo obtenido, iniciar otro, esta vez no ya el de cumplimiento, sino tal vez el contencioso administrativo o el amparo, que tuviera por finalidad efectuar un control acerca de la legalidad y/o constitucionalidad del acto administrativo expreso.

Ahora bien, esta inactividad que origina una controversia para ser ventilada en un proceso de cumplimiento, no sucede lo mismo con la inactividad material, pues en tal supuesto, al margen de un procedimiento administrativo, se genera un no hacer que era exigido por la ley o en un acto administrativo. Frente a tal inactividad, no rige la técnica del silencio administrativo negativo, desde que no existe petición de particular formulado que requiera pronunciamiento, sino una simple carencia de actuación que se presenta como contraria a la ley o a un acto administrativo.

Es este tipo de inactividad de la Administración la que se controla mediante el proceso. En ese sentido, bien puede decirse que la inercia, la mora o la omisión, términos todos ellos que aquí tomamos como sinónimos, de un hacer que es obligatorio, ha de constituir la "omisión lesiva" en el proceso de cumplimiento. 
Dentro de aquel concepto de "omisión lesiva" no se encuentra la inactividad formal de la Administración, tampoco lo está la posibilidad de impugnar actos administrativos. Como lo ha expresado el Tribunal Constitucional peruano (STC $\mathrm{N}^{\circ}$ 486-98-AC/ TC), la impugnación de un acto, que dejó a su vez sin efecto una resolución que eventualmente establecía un derecho subjetivo, no puede entenderse dentro de los alcances del Proceso de Cumplimiento, pues mediante éste se persigue obtener su cumplimiento, que es una cuestión absolutamente distinta a la impugnación.

\section{TiPología de LA INACTIVIDAD MATERIAL DE LA ADMINISTRACIÓN}

A fin de distinguir la diversidad de comportamientos materialmente omisivos de la Administración:

\subsection{Por los alcances de su in- cumplimiento}

i. Omisión total. Presupone una pluralidad de obligaciones impuestas por una norma legal o un acto administrativo, respecto de las cuales ninguna es debidamente cumplida. En tal supuesto, a través del proceso de cumplimiento se procurará que todas ellas se cumplan.

ii. Omisión parcial. Las omisiones parciales, en cambio, suponen el cumplimiento de algunas de las obligaciones que le han sido impuestas, pero que no alcanzan la totalidad. En la medida que sólo algunas han sido ejecutadas, el proceso de Cumplimiento, en un supuesto semejante, se destinará a exigir que la autoridad o funcionario cumpla con realizar los extremos de la obligación aún pendientes, no pudiéndose invocar en tal caso la sustracción del objeto de la controversia, pues, siguiendo a Ignacio Burgoa, la cesación de los efectos de la omisión reclamada sólo se producirá cuando desaparezca totalmente la ausencia de actuación administrativa, y no cuando ella fuera solamente parcial.

\subsection{Por la naturaleza del man- dato que se impone:}

i. Omisiones de actos debidos al ejercicio de potestades discrecionales. En ocasiones la ley o el acto administrativo, al establecer una serie de tareas a los órganos de la Administración, deja al funcionario o autoridad un margen de libertad en la concretización de lo previsto.

Como anota Marienhoff, analizando el tema de los actos administrativos discrecionales, en tales supuestos "la Administración no está constreñida por la norma a adoptar determinada decisión: en presencia de determinados hechos o situaciones, queda facultada para valorarlos o apreciarlos, y resolver luego si, de acuerdo a tales hechos o situaciones, se cumple o no la finalidad perseguida por la norma; en el primer supuesto hará lugar a lo que se le hubiere solicitado, en el segundo caso lo desestimará".

Aunque las normas que desarrollan el proceso de cumplimiento no distingan esta clase de omisiones, el artículo $4^{\circ}$ de la Ley $N^{\circ} 23506$, derogada por el Código Procesal Constitucional, aplicable por analogía al caso del proceso de cumplimiento, restringió el control de estas omisiones, ya que éstas deben consistir en omisiones derivadas de un "acto debido" y no de concretización bajo la libre apreciación del funcionario o autoridad investido de tales potestades.

ii. Omisiones de obligatorio cumplimiento. Están constituidas por aquella inactividad en la que, a diferencia de la anterior, la Ley o el acto administrativo impone un deber de actuar cierto

\subsection{Por la condicionalidad del mandato:}

i. Omisiones derivadas de un mandato condicional. Son aquellas que se producen cuando las obligaciones impuestas a los órganos de la administración no se tornan exigibles en tanto no se cumplan algunos supuestos de hecho o de derecho que la propia norma o el acto administrativo exigen a fin de hacer exigible la prestación.

Debe diferenciarse este tipo de omisiones, de las que pudieran presentarse como consecuencia del ejercicio de una potestad discrecional atribuida al órgano de la Administración. Las primeras, de cumplirse los supuestos que la norma o el acto determinan, exigen irremediablemente una actuación administrativa en dirección a satisfacer las obligaciones previstas en la norma o el acto administrativo. Las segundas, no imponen la satisfacción de condiciones, sino dejan un margen de libertad dentro del cual se desenvuelve la actuación administrativa, la que dictará o ejecutará lo dispuesto en la ley o el acto administrativo de evaluarlo positivamente. 
Respecto de estas omisiones, el proceso de cumplimiento sólo podrá prosperar siempre que el reclamante pruebe que se han cumplido todas las exigencias de hecho o derecho que se exigen, encontrándose la ausencia de actuación administrativa en calidad de arbitraria por ser ilegal; en caso contrario, esto es, que no se pruebe o, en su caso, el actor no se encuentre en el supuesto de hecho exigido por la norma o el acto administrativo, el proceso de cumplimiento no podrá prosperar.

ii. Omisiones derivadas de un mandato formulado incondicionalmente. A diferencia de la anterior, tal omisión es posible de observarse tras la carencia de actuación administrativa exigida directa y predeterminadamente por la ley o el acto administrativo. Supone un mandato concreto, en el que no hay supuesto de hecho o situación jurídica que los órganos de la administración deban evaluar, pues se trata de un mandato que exige un actuar de la Administración no vinculado a elementos externos de la norma o al acto administrativo.

Esta característica del mandato, el de su incondicionalidad, ha sido un aspecto que, en el Perú, los órganos de la jurisdicción constitucional han destacado tempranamente desde sus primeras sentencias al evaluar si la omisión que se reputaba como lesiva al principio de legalidad era susceptible de condena a través del proceso de cumplimiento.

5.4. En función de la complejidad de instrumentalización de la actuación administrativa i.- Omisiones derivadas de mandatos de instrumentalización compleja. La distinción de esta clase de eventuales omisiones de actuación administrativa está vinculada directamente con la complejidad del mandato contenido en la ley o un acto administrativo impuesto al órgano de la Administración. Así, una carencia de actuación administrativa bien puede no deberse a razones meramente arbitrarias, sino a obstáculos materiales de la Administración en su implementación (infraestructura, carencia de medios económicos, recursos humanos, etc.).

Frente a tales supuestos, bien puede declararse la ilegalidad de la ausencia de actuación administrativa, pero ello de poco o nada podría servir si es que, al tiempo de expedirse un mandato judicial, los órganos de la Administración se encontrasen imposibilitados materialmente de poderlo hacer. Desde luego, que no se trata tampoco de desestimar la pretensión en tales casos, pues creemos que en ese supuesto el Juez deberá de realizar una evaluación en torno al grado de complejidad del mandato previsto en la norma o el acto administrativo; juzgar si, tratándose de actos que requieren nuevos gastos, se ha cumplido con la regla de su instrumentalización "progresiva" (o no); así como, entre otros aspectos, que el incumplimiento haya excedido un plazo razonable.

ii.- Omisiones derivadas de mandatos de instrumentalización simple. Es la inactividad material de actuación administrativa frente a un deber legal o administrativo exigido, que no obstante requerir de simples actos, no son efectuados, por lo que cabe deducir su arbitrariedad. Tales omisiones normalmente lo son de deberes ordinarios impuestos en la actividad que realizan, y para lo cual cuentan con medios técnicos, humanos y materiales asignados.

\subsection{Por la conservación de la inactividad administrativa}

i.- Inactividad administrativa subsistente. En tanto que mecanismo destinado a efectuar el control de la inactividad material de la Administración, se exige que las omisiones cuya ilegalidad se pretendan dilucidar en su seno se encuentren vigentes, esto es, que no se haya realizado la actuación administrativa que exigía se realice la ley o el acto administrativo, encontrándose la autoridad o funcionario obligado, en condición de renuencia latente.

Es necesario, además, que el mandato legal o administrativo se encuentre también vigente, $y$ no que haya sido derogado, cesado en su vigencia o, en el caso de los actos administrativos, anulado o declarado nulo. Son omisiones subsistentes en tanto que mantienen en vigencia, por un lado, el incumplimiento de lo exigido y, de otro, la norma o acto de donde se deriva el mandato.

ii.- Inactividad administrativa insubsistente. Por el contrario, si la obligación de cumplir con lo dispuesto en la ley o en el acto administrativo ha desaparecido, bien sea por haberse realizado la prestación total de lo exigido, o bien porque la ley o el acto administrativo que preveía la obligación ha sido derogado o cesado en su vigencia, se estará 
al frente de una inactividad insubsistente.

\subsection{Según la evidencia de la lesión}

i. Arbitrariedad manifiesta de la inactividad administrativa. La inactividad material de la Administración, para ser controlada a través del proceso de Cumplimiento, debe ser consecuencia de un mandato concreto, claro o evidente, cuyo desconocimiento u omisión aparezca como inequívoco y sin justificación alguna.

Es manifiestamente arbitrario, precisamente, porque frente ante una obligación de hacer incondicional y de cumplimiento obligatorio, la autoridad responsable se niega a cumplir deliberadamente con lo dispuesto en la ley o en el acto administrativo. Tal arbitrariedad, sin embargo, no solamente cabe predicar respecto de las omisiones derivadas de un mandato impuesto incondicionalmente, pues puede presentarse también respecto de los mandatos u obligaciones cuya realización se deja librada al cumplimiento de determinados supuestos de hecho o de derecho. En tales casos, constituirá una omisión manifiestamente arbitraria si, cumpliéndose los supuestos de hecho y de derecho que la ley o el acto administrativo prevén, sin embargo, éste no se realiza.

La manifiesta arbitrariedad de la inactividad material de la Administración, en tales casos, aparece como una omisión inequívoca y perceptible, que no requiere de mayor probanza que la mera constatación de la omisión del funcionario o autoridad de cumplir con la ley o la autovinculación administrativa derivada de una obligación impuesta.

ii. Inactividad administrativa no manifiesta. A diferencia de la anterior, constituirá una inactividad de arbitrariedad no manifiesta, cuando la determina- ción de lo exigido no aparezca en forma indubitable de la ley o el acto administrativo o bien porque se requiera de un mínimo debate probatorio que lleve al Juez a la convicción de que no se cumple o acata el mandato (caso, por ejemplo, de los mandatos contenidos en la ley o en el acto administrativo, de condiciones complejas, cuya determinación de si fueron satisfechas o no pasa por un debate probatorio más amplio del que puede brindar el proceso de Cumplimiento).

\section{A MODO DE CONCLUSIÓN}

Las características del mandamus son las que fundamentan la procedencia de un proceso constitucional de cumplimiento que acredita la renuencia del funcionario o autoridad pública y que busca sancionar la inactividad de la Administración y manifestar el obligatorio cumplimiento que reviste el acto administrativo, el mandato legal y de la orden de emisión de una resolución o de un reglamento. 
